\title{
¿CLÁSICO O TÉCNICO? EL BACHILLERATO Y LA ENSEÑANZA SECUNDARIA EN COLOMBIA, 1903-1956 ${ }^{1}$
}

\author{
Oscar de Jesus Saldarriaga ${ }^{2}$ \\ Rafael Galindo Reyes ${ }^{3}$
}

\section{RESUMEN}

En Colombia, el sistema educativo nacional moderno -escalonado, público y abierto- inició hacia 1892, en un complejo juego de tensiones entre el Estado y la Iglesia, el sector privado y el sector público; la concepción humanista-elitista y la concepción democrática-diversificada; poderes centrales y elites locales por financiación, autonomía y uniformidad. El Estado sostuvo un sistema de bachillerato humanístico selectivo. Cuando surgieron propuestas más democratizadoras, tanto el Estado como las élites intelectuales se han rehusado a asumirlas como proyecto nacional.

\footnotetext{
${ }^{1}$ Los autores agradecen a la historiadora Liliana Martínez Sarmiento con quien discutimos en permanencia estas hipótesis y fuentes, y a Alejandra Muñoz Restrepo por su apoyo bibliográfico.

2 Pontificia Universidad Javeriana, Bogotá, Colombia.

3 Pontificia Universidad Javeriana, Bogotá, Colombia.
} 
Palabras clave: Colombia, bachillerato, enseñanza secundaria, sistema de instrucción pública, Escuela Única.

\title{
CLÁSSICO OU TÉCNICO? O ENSINO SECUNDÁRIO NA COLÔMBIA, 1903-1956
}

\section{RESUMO}

Na Colômbia, somente em 1892 se iniciou o sistema educacional nacional moderno-faseado, público e democrático, cruzado por um complexo jogo de tensões, entre elas: Estado e Igreja, setor privado e setor público; concepção humanista-elitista e concepção democráticadiversificado participação dos poderes centrais e elites locais no financiamento, autonomia e uniformidade. O Estado Colombiano insistiu no controle de um sistema hierárquico, no entanto, quando emergiram propostas mais democratizantes, tanto o Estado como as elites intelectuais se recusaram a aceitá-las como um projeto nacional.

Palavras-chave: Colômbia, ensino secundário, sistema de instrução pública, educação humanística, escola unificada.

\section{CLASSIC OR TECHNICAL? SECONDARY SCHOOL IN COLOMBIA, 1903-1956}

\begin{abstract}
In Colombia, until 1892 starts the process of shaping a modern national education systemstaggered, public and democratic-, crossed by a complex set of tensions, including: between the state and the Church, the private sector and the public sector; the Humanist-elitist and the democratic-diversified conceptions of the baccalaureate; and a tension between central and local elites, for funding, autonomy and uniformity. The state pawned in controlling a hierarchical system. But when more democratizing proposals emerged, both the state and the intellectual elites refused to assume them as a national project.
\end{abstract}

Keywords: Colombia, baccalaureate, secondary education, public instruction system, unified school.

\section{CLASSIQUE OU TECHNIQUE? L'ENSEIGNEMENT SECONDAIRE EN COLOMBIE, 1903-1956}

\section{RÉSUMÉ}

En Colombie, ce n'est que jusqu'à 1892 que le processus de formation d'un système éducatif national moderne, échelonné, public et démocratique démarre, marqué par un ensemble de tensions, y compris: entre l'État et l'Église catholique, entre le secteur privé et le secteur public; entre la conception humaniste-élitiste versus la démocratisation; des tensions entre puissances centrales et élites locales pour le financement, l'autonomie et l'uniformité. L'État a misé sur le contrôle d'un système de baccalauréat hiérarchique. Mais lorsque des projets plus 
démocratiques ont émergé, tant l'État que les élites intellectuelles ont refusé de les assumer comme un projet national.

Mots-clés: enseignement secondaire, Colombie, système éducatif public, école unique, démocratisation. 


\title{
LA PROMESA DE LA MODERNIDAD EDUCATIVA (MEDICIONES POLÍTICAS)
}

\begin{abstract}
En un cierto sentido, toda la historia de los sistemas educativos y formas de enseñanza en los siglos XIX y XX puede hacerse a partir del paso y las consecuencias de dicho paso desde la inclusión parcial, y por tanto, la no escolarización y exclusión parcial de una parte de la población, a la presencia simultánea de procesos de inclusión más o menos generalizada a lo largo del tiempo, acompañados de procesos de exclusión y expansión compensatoria de otras partes del sistema, es decir de procesos de diferenciación o segmentación que implican la exclusión de ciertas trayectorias o modalidades y la inclusión en otras. En especial en lo que a enseñanza secundaria se refiere, una vez alcanzado un alto índice de inclusión en el nivel primario (VIÑAO, 2002, p.37).
\end{abstract}

"La segunda enseñanza constituye hoy en todas las naciones un problema no resuelto", es la frase de la famosa Exposición de motivos del Real Decreto de reforma de la segunda enseñanza de 19 de julio de 1900 en España, con que el historiador Antonio Viñao abre su reflexión sobre el paso del bachillerato de élite a la secundaria para todos. (VIÑAO, 2011b, p. 449). Frase que buena parte de los reformadores educativos de inicios del siglo XX repitieron.

Pues bien, llegados ya al final de la segunda década del siglo XXI se puede afirmar, bajo la lente del historiador, que las sucesivas reformas del sistema educativo colombiano en el siglo XX no han logrado resolver el problema de la enseñanza secundaria.

Acogemos la riqueza analítica de la tesis de Viñao respecto del juego complejo entre "procesos paralelos de inclusión, exclusión y expansión compensatoria" (2002, p. 47), para leer los movimientos históricos entre el bachillerato y la enseñanza secundaria. Pero pongamos entre paréntesis -duda metódica de historiador- la sugerencia de un proceso evolutivo de los sistemas educativos que pasarían globalmente de la inclusión parcial o selectiva (casi exclusión) a la inclusión generalizada (con gradaciones y condiciones). Nuestro 
método toma distancia de toda noción de evolución, y asume los costos de la noción de discontinuidad tal como se formula en la Arqueología del saber (FOUCAULT, 1970, p. 13-14).

Esta duda tiene un sustento teórico. Se trata de considerar el carácter general de la promesa educativa de la modernidad: sabemos que la escuela moderna se instituye y se legitima desde el siglo XVII gracias al legendario mandato comeniano, enseñar todo a todos. $\mathrm{Y}$ cuando los estados nacionales en el siglo XIX buscan construir sus sistemas educativos, este mandato, proclamado luego como un derecho humano, se convierte en la gran panacea de las sociedades liberales. De modo correlativo, la historia y la historiografía de la educación moderna se van constituyendo como un registro, cada vez más científico, de los éxitos y fracasos locales, nacionales, globales en la consecución del ideal: del lado de los planificadores y administradores de los sistemas, tendremos el relato de las difíciles realidades que se han opuesto a que el 100\% de esta promesa no se haya realizado (aún) para sus gobernados. Y para éstos, esa historia es el relato de las arduas luchas con que han ido derrotando los incumplimientos que (todavía) se interponen a la realización efectiva de sus derechos.

Así, la promesa educativa de la modernidad se construye como un principio sencillo y eficaz que legitima el funcionamiento del sistema por un juego de "doble vínculo" (double bind); esto es, legitima las recurrentes reformas educativas tanto como las incesantes luchas de maestros, estudiantes, padres de familia y ciudadanos alrededor del derecho a la educación. Parece que todo se decidiera en los continuos pulsos a que se libran los actores sociales, pues las tensiones se tramitan en los ascensos o descensos de puntos porcentuales en las estadísticas. En los medios de comunicación se escuchan todo el tiempo frases como: «hemos alcanzado el 100\% de cobertura en primaria...", «la reforma en curso se propone aumentar la cobertura en secundaria, que, a decir verdad, está un poco deficiente...»; «es escandaloso que sólo el 50\% de los estudiantes inscritos en primaria hayan alcanzado el nivel de 
secundaria...»; «no cesaremos en la lucha por el derecho a una educación secundaria y universitaria gratuita y de calidad para todos».

De este modo, debemos concluir que la lógica propia del sistema educativo moderno, la ambivalente lógica que lo hace creíble desde sus comienzos, es la de la lenta pero segura inclusión progresiva; y el paso de un momento excluyente a un momento incluyente sería sólo el momento en que, para cada estado-nación, el umbral de cobertura educativa ha alcanzado el punto de equilibrio (simbólico) del 50\%. Esta lógica de double bind autorizará a quienes dicen que la enseñanza secundaria nunca dejará de ser un mecanismo de exclusión, tanto como a quienes sostienen que su objetivo será siempre la inclusión.

Todo ello se vuelve a simplificar en los momentos en que hay que presentar balances concretos ante la opinión pública. Así, El Tiempo, el diario de mayor circulación nacional en Colombia informaba hace poco que:

Según cifras del Ministerio de Educación, con corte al mes de agosto del 2015, solo el 41,2 \% de los estudiantes de colegios oficiales y el 56,4 $\%$ de no oficiales, para una tasa de $48,5 \%$, aparecen en los registros de absorción a la educación superior. Esto quiere decir que de 100 estudiantes que finalizaron grado 11, solo 48 ingresaron a la educación superior el año inmediatamente siguiente a culminación de la media (MALAVER, 2016, p. 1).

El periodista consulta a un experto, quien declara:

Hay jóvenes que no pueden ingresar a cursar estudios técnicos o a una universidad, por la mala educación que han recibido durante su bachillerato; esto se une a su condición de pobreza. Esos factores generan barreras de acceso", dijo [el profesor] Sánchez, de la Facultad de Economía de la Universidad de [...] (MALAVER, 2016, p. 1).

El artículo continúa presentando los índices de deserción, más alarmantes que los de absorción: 
En cuanto a cifras de deserción escolar y en la educación superior, estas siguen siendo preocupantes. Según el Ministerio de Educación (MEN), en el 2015 fue de 3,6 en los colegios oficiales y de 3,1 en los no oficiales. Este mismo índice fue de 10,1 \% (2014) y 9,25 \% (2015) en educación superior (MALAVER, 2016, p. 1).

Estos índices se agudizan al desagregarse, continúa el artículo:

Según el Sistema para la prevención de la deserción en educación superior (Spadies) del Ministerio, el $50 \%$ de los estudiantes que ingresan a educación superior desertan, 70\% de los cuales lo hacen en los primeros cuatro semestres por razones principalmente asociadas a sus falencias académicas. Por esta razón, la SED (Secretaría de Educación Distrital) explica lo importante de la existencia de mayores recursos para el acceso, pero con estrategias que garanticen mayores posibilidades de que dicho estudiante permanezca una vez ingrese a la universidad (MALAVER, 2016, p. 1).

No haremos comentarios, el presente artículo será nuestro comentario al reiterado ritual de porcentajes que dan valor de autoridad científica a las políticas educativas contemporáneas en Colombia. Sólo una precisión: cuando en nuestro país se habla hoy de educación superior, se está incluyendo a la denominada educación técnica y profesional, que no es reconocida como formación de nivel universitario. Esto es, a juicio de los defensores del Derecho a la Educación, un manejo político de la estadística, que permite mejorar las cifras para mostrar.

El mismo artículo deja traslucir la operación, cuando se refiere a la estrategia de la SED para dar apoyo financiero (créditos) a los egresados de la llamada Educación media:

La gestión de la Secretaría se está dando para que el 100 \% de esa inversión se produzca en educación superior. Por esta vía se proyectan 3.900 cupos. La proporción que se espera apoyar es de 70\% en técnica profesional y tecnológica y $30 \%$ de profesiones universitarias (MALAVER, 2016, p. 1). 
La complejización de las cifras es también un instrumento de lucha y negociación entre ambos bloques. En Colombia, una Alianza entre Empresarios y ONG's democráticas, llamada Educación, Compromiso de Todos, presenta regularmente estados del cumplimiento de metas del Derecho a la Educación, y para tal efecto ha creado un complejo indicador. La prensa lo refleja así:

Faltan tan solo 46 puntos para llegar a los 100 necesarios para cumplir la garantía del derecho a la educación [...] El Índice al Derecho a la Educación (IDE), herramienta diseñada a partir de las recomendaciones del Comité de Derechos Económicos, Sociales y Culturales de la ONU, muestra que faltan 46 puntos para llegar a la meta de 100. [...] Educación Compromiso de Todos, alianza conformada por las fundaciones Corona, Empresarios por la Educación, Restrepo Barco y Saldarriaga Concha, así como la Corporación Región, Unicef y el Centro de Investigación y Formación en Educación-Cife de la Universidad de los Andes, presentarán al país el Índice del Derecho a la Educación (IDE).[...] Con 62 indicadores, reunidos en cuatro dimensiones: Disponibilidad, Accesibilidad, Adaptabilidad y Aceptabilidad, la Alianza diseñó el IDE con valores entre o y 100 [...] En los dos años analizados por la Alianza, 2012 y 2013, el resultado mostró que el país está a medio camino. En 2012 quedó en $55 \%$ y en 2013, 54.3\%. La reducción se explica por la disminución de los puntajes en las dimensiones de Aceptabilidad y Adaptabilidad, [...] siendo por ejemplo, el eje central para medir la Adaptabilidad "la permanencia y la matrícula de poblaciones vulnerables (etnias, afectadas por la violencia y en situación de discapacidad"). (UNIVERSIA, 2014)

Esta imprecisa precisión 4 nos remite al corazón del problema que nos ocupará, y a la tesis que queremos sostener: esa crisis perpetua del bachillerato, su atrapamiento en el círculo vicioso de la escasez de recursos de la población y la baja calidad de la educación es, no una causa, como quieren los expertos, sino un síntoma. Pero ¿̇síntoma de qué?

4 "Imprecisa precisión": expresión acuñada por el filósofo e historiador Étienne Gilson para referirse al estilo de escritura de las Encíclicas pontificias, y el método para leerlas. (GILSON, 1962, p. 261). 


\section{DE UNIVERSIDADES A COLEGIOS: EL PARADÓJICO SURGIMIENTO DEL BACHILLERATO MODERNO}

El término bachillerato ha experimentado múltiples acepciones según tiempos y lugares, algunas de ellas contradictorias, si nos remontamos a sus primeros usos desde el siglo XV (VIÑAO, 2011B). No menos ocurre con la denominación compuesta, bachillerato moderno. Para abordar tal polisemia histórica, debemos recoger algunas distinciones. La primera y más general, consiste en no confundir el grado de bachiller (el primer grado universitario propio de las Facultades de antiguo régimen, que eran corporaciones estamentales), con el bachillerato como un nivel intermedio - en una escala ascendente -, a la vez preparatorio - para estudios superiores - y terminal - para entrar al mercado laboral -; público - financiado y regulado por el Estado -, y en fin, democrático -abierto a todas las clases sociales para garantizar la igualdad de oportunidades y la movilidad social-.

Luego del problema semántico, nos queda por abordar el problema histórico de las continuidades y rupturas entre los dos modos de funcionamiento. la distinción moderna entre "bachillerato" (estudios que conducen al nivel universitario) y la "educación secundaria", estudios postprimarios que conducen a formaciones laborales u oficios técnicos. Se supone que el bachillerato es una de las modalidades de la secundaria como nivel intermedio. En efecto, los historiadores de la enseñanza secundaria han caracterizado el surgimiento del bachillerato (moderno) como el desprendimiento de ciertos cursos de las antiguas Facultades de Artes, más tarde, de Filosofía. Viñao señala que desde fines del siglo XIX, ya Giner de los Ríos denunciaba que la única finalidad académica de la segunda enseñanza era propedéutica: preparar a un grupo social restringido para las carreras universitarias. De ahí, añadía, que "no sólo se halla separada de la primera [enseñanza] bruscamente, sino que, por su origen, [la Facultad de Filosofía] ha conservado su filiación esencialmente universitaria, en su sentido, su estructura, 
su organización pedagógica, sus métodos, y hasta muchas veces [...] en la formación de su profesorado" (VIÑAO, 2011B, p. 32). Hasta hoy, la crítica recurrente es que el bachillerato, durante mucho tiempo, ha sido la vía única -y excluyente- de acceso a la universidad. De hecho, estas tensiones estructurales fueron tan evidentes y difíciles desde el comienzo, que desde el siglo XIX hasta el presente, en muy buena parte de las naciones occidentales y occidentalizadas, el logro de "una enseñanza secundaria para todos", según la consigna del historiador, pedagogo y líder laborista inglés R. H. Tawney en 1924 (TAWNEY, 1932), se ha considerado como un problema irresuelto (VIÑAO, 2002, 2011a).

Es cierto que, por una parte, cada caso nacional ha vivido una evolución singular, dado que cada una de las ya enunciadas características del bachillerato nacidas de la promesa de la modernidad educativa, enseñar todo a todos, han experimentado un desarrollo desigual y combinado. Pero, por otra parte, constatamos una estructura común: "el origen universitario" del bachillerato, que marca hasta hoy sus dinámicas paradójicas. ¿Cómo analizar esta crisis perpetua del bachillerato, su atrapamiento en el círculo vicioso de la inclusión y la selectividad?

Frente a este rompecabezas historiográfico, tratamos de sortear dos riesgos analíticos: de un lado, evitar los relatos de fracaso que surgen de comparar los proyectos y promesas con las realidades efectivas; y por otro lado, evadir los relatos nihilistas que presuponen que todo ideal es una mentira o una trampa del sistema. Así, para romper este círculo vicioso, proponemos introducir un tercer elemento analítico: entre la promesa ideal y la precariedad de las realidades logradas sería posible entrever la emergencia de unos efectos no previstos, no conscientes, un poco causados y un poco determinados; efectos que van estructurando el dispositivo a la vez heterogéneo y polifuncional de lo que, para nuestro asunto, reconocemos como enseñanza secundaria o bachillerato.

Tomaremos el caso colombiano, que proponemos tratar con la metodología de Michel de Certeau para el saber histórico: en lugar de usar la 
particularidad del caso para ilustrar el modelo histórico evolutivo, es posible someter a prueba tal modelo a partir de la singularidad del caso. Un trabajo sobre los limites (DE CERTEAU, 1975, p. 110) mostrará la disfuncionalidad singular del bachillerato colombiano, metiendo un poco de ruido en el esquema clásico de modernización de los sistemas educativos iberoamericanos en el siglo $\mathrm{XX}$, el esquema de "centralización, secularización, populismo y desarrollismo" (OSSENBACH, 2004, p. 24).

\section{GÉNESIS DEL BACHILLERATO CLÁSICO: UNA ARISTOCRACIA HUMANÍSTICA}

Algunos trabajos sobre el proceso educativo durante el siglo XIX colombiano, han mostrado que el famoso descenso de las materias universitarias preparatorias no ocurrió como una evolución progresiva y natural (SALDARRIAGA, 2008; 2014). Bien al contrario, la tendencia dominante hasta finales del siglo XIX fue la inversa: en medio de un intrincado juego de tensiones Estado/Iglesia, público/privado, derecho/ciencias útiles la pugna entre las élites centrales y las élites locales por el acceso a títulos universitarios en Bogotá o autorizarlos en los Colegios y Casas de Educación de las provincias (SAFFORD, 1989), fortaleció, paradójicamente, el valor estratégico de la Facultad de Filosofía y Letras. Por ello, su crisis se retardó hasta 1892, fecha de la creación del bachillerato moderno enseñanza secundaria escalonada en Colombia, mientras las fechas homólogas fueron, en Francia 1808, en Prusia 1812, y en España 1834. Además de tardío, este proceso tuvo marca confesional, pues bajo la Constitución de 1886 se firmó un tratado concordatario con la Santa Sede -vigente en buena parte hasta hoy-, encargó la dirección intelectual y moral de la instrucción pública a la Iglesia católica, poniendo además los recursos públicos a su disposición (CONCORDATO, 1887). Hasta el punto en que, señala la historiadora Aline Helg, si bien los documentos hablan de "educación oficial" o "pública", ello no significó la existencia de 
una enseñanza difundida por el Estado en oposición a una enseñanza privada dada por los particulares. Un colegio era "oficial" si sus edificios eran propiedad de la nación o del departamento. La enseñanza oficial no existía; además Colombia no disponía de una escuela normal para los maestros de secundaria. El Estado confiaba por contratos la dirección de sus establecimientos a particulares o a congregaciones religiosas" (HELG, 1987, p. 73).

Dos glosas sobre esta anomalía nos permitirán proponer un panorama esquemático de las tensiones y fisuras del proceso de configuración del bachillerato colombiano en esta primera mitad de siglo.

\section{PRIMERA GLOSA: "REDES DE ESTABLECIMIENTOS DIVERSOS"}

Tras descartar la nebulosa distinción público/privado, Helg (1987) identifica cuatro grupos de colegios a lo largo del siglo: 1) Los dirigidos por comunidades religiosas católicas, más del 50\% de los establecimientos secundarios, establecidos en algunas capitales departamentales, pero en buena parte aún concentrados en Bogotá); 2) Colegios dirigidos por civiles colombianos (40\%, situados usualmente en las ciudades pequeñas) y católicos por inercia cultural. El 10\% restante: 3) Colegios dirigidos por liberales (minoría de oposición a la enseñanza confesional); y 4) Colegios extranjeros laicos, en principio para los nacionales de países como Estados Unidos, Francia, Alemania o Inglaterra, y que al igual que los liberales, se contaban en los dedos de una mano (HELG, 1987, p. 74-75); hoy un buen sector de la élite colombiana se educa en ellos. Sólo hacia 1936 aparecerá un quinto grupo: el de los colegios públicos nacionales, poco numerosos (alrededor de 25 en 1948), buena parte eran colegios privados prestigiosos que fueron nacionalizados. "A partir de 1948, el Ministerio no abrió ningún colegio” (HELG, 1987, p. 174, 277). Y sólo hasta 1969 el Estado asume un verdadero proyecto de creación de una red de colegios nacionales (FACUNDO Y ROJAS, 1982), los Institutos Nacionales de 
Enseñanza Media Diversificada (Inem), que hoy, a 2018, apenas llegan a 19 en todo el país.

Este es el escenario fragmentado en el que el Estado ha sido una entre entre las distintas fuerzas que buscan su autonomía o su hegemonía en este tipo de "sistema educativo" caracterizado por lo que un historiador francés de la educación llama "redes yuxtapuestas de establecimientos diversos" (PROST, 2004, p. 702). Se trataba de gobernar las tensiones no resueltas del siglo XIX en cuanto a la autonomía del Estado respecto de la Iglesia católica, de la centralización de los poderes locales, de la formación de una élite humanista pero orientada a la ciencia y la tecnología, con las exigencias del siglo XX, esto es, diversificar la secundaria hacia múltiples actividades profesionales, y democratizar la sociedad, abriendo el sistema educativo a sectores sociales medios y populares.

Pues bien, de un lado, bajo el auspicio estatal, las más importantes comunidades religiosas docentes masculinas europeas (jesuitas, lasallistas, salesianos, maristas) y también muchas comunidades religiosas femeninas, se instalaron en diversas regiones del país. "De 1870 a 1900, sumándose a las órdenes presentes desde el periodo colonial, (los menores franciscanos, los dominicos, los jesuitas y los agustinos recoletos), 12 comunidades femeninas y 8 masculinas se establecieron en el país; de 1900 a 1930, el movimiento prosiguió con la llegada de 24 nuevas congregaciones (17 femeninas y 7 masculinas)" (HELG, 1987, p. 76). Así, imprimieron su formato curricular y su disciplina a los colegios, tanto a las viejas instituciones heredadas del periodo colonial (el Colegio de San Bartolomé y el Colegio del Rosario) como a los establecimientos recién creados que empezaron poco a poco a proliferar a lo largo del siglo XX. El bachillerato humanístico -hoy llamado académico - tras la supresión del latín desde 1963 no ha terminado hoy de ceder su estatuto de puente único a la educación universitaria, así como ésta tampoco ha abierto sus modalidades a la diversificación profesional, y en especial, a las técnicas. (GÓMEZ, 2009 y 2015).

De otro lado, desde la Ley 39 de 1903 y sus decretos reglamentarios de 
1904 y 1905 (conocidos como la Ley Uribe) se advierte la debilidad financiera del Estado central para sostener al menos un sistema nacional de enseñanza primaria: el estado central sólo aportaba el material escolar y fijaba los programas, pero no podía asegurar los nombramientos de los funcionarios inspectores y maestros - de nivel departamental o municipal. Todo el control quedaba en manos de los gobernadores departamentales y las juntas municipales, en las que los párrocos tomaban parte activa. Y la secundaria quedaba mucho más desarticulada. Por una parte, el Poder Ejecutivo central se comprometía a financiar y a inspeccionar los colegios secundarios para todo el territorio (Ley 39, art. 4), pensando idealmente en sostener al menos un colegio nacional en cada capital de departamento,

[...] pero la ley de 1903 dejó la puerta abierta a los departamentos y municipios para crear sus propios establecimientos, dispensando así a la autoridad central de la obligación de difundir toda la enseñanza secundaria. (HELG, 1987, p. 103).

Por su parte, el Estado central gestionaba los colegios oficiales bajo la modalidad de contratos individuales, abriendo las puertas a las negociaciones con cada red: las de las comunidades docentes, las de los gamonales departamentales, las de los empresarios particulares, las de las colonias de extranjeros. Como único instrumento de intervención, el Estado central disponía de la potestad de inspección: la instauración de controles burocráticos sobre tres aspectos donde todos los establecimientos, oficiales y privados, podían ser presionados: uno, el cumplimiento de normas de higiene y seguridad en los establecimientos educativos; dos, la validación central de los títulos académicos expedidos por cada institución, -que en periodos de mayor intervención se tradujo en el requisito de exámenes estatales de verificación de conocimientos - y tres, la potestad de regular el contenido del pensum y el número de asignaturas exigidas a todos los colegios que querían ser reconocidos por el Estado (HELG, 1987 p. 114). 
Así las cosas, se diría que para el Estado colombiano se trató, según la trayectoria clásica de construcción de los sistemas educativos nacionales, de ganar espacio para la instrucción pública, gratuita, obligatoria y laica frente a los poderes de la institución eclesial y de los particulares (RINGER, MULLER, SIMON, 1987). Y que esa tarea fuese impulsada por el partido liberal, en conflicto con el partido conservador, defensor del estatus de la Iglesia católica. Ahí comienzan las anomalías: de entrada, si el tema de la neutralidad religiosa en las escuelas oficiales era inaceptable por Concordato, la tolerancia de cultos estatuida en la Constitución garantizaba legalidad a la existencia de instituciones privadas, en el caso, liberales o protestantes, así fueran blanco constante de descalificación ante la opinión pública. Además, las transformaciones socioeconómicas y el contexto liberal hegemónico a finales del siglo XIX imponían al catolicismo, incluso en un país confesional, ciertas reglas de juego mínimas para mantener su legitimidad, entre ellas la aceptación del progreso técnico-científico y de la validez de las ciencias experimentales. En Colombia, esta circunstancia se manifestó no sólo a través de una minoría liberal opositora, sino también en el campo gubernamental, controlado hasta 1930 por un sector conservador modernizante, el cual, sin tocar directamente el acuerdo concordatario, presionó por ampliar el poder estatal para reformar el sistema educativo en función de la creciente división social del trabajo y, hacia la ampliación de las demandas sociales de las clases medias y de los trabajadores. Esto con mucha más parsimonia (HELG, 1987, p. 131).

Por ello, desde la promulgación de la legislación orgánica (la Ley 39 de octubre de 1903 y el decreto reglamentario 491 de 1904, conocidos como la "ley Uribe" que rigieron hasta 1928), el efecto práctico en lo administrativo siguió siendo un estado de cosas caracterizado por negociaciones e hibridaciones entre lo público y lo privado, lo civil y lo religioso, lo técnico y lo político, lo conservador y lo liberal. Se establecían, y para todo el siglo XX, las tensiones y las fisuras entre la centralización (o nacionalización) y la privatización, que han terminado por crear dos sistemas paralelos brutalmente desiguales: educación privada para ricos y educación pública para los pobres. 
Apoyados en las cifras del Informe Lebret para 1958, calculamos en 14\% el margen del avance educativo estatal sobre el sector privado en el periodo 1923-1953:

El número de alumnos matriculados [en secundaria] era de 65.618 en 1953; llegaba a 45.678 en 1946, o sea un importante aumento del $43 \%$, mientras que el aumento de la población en general fue de una cuarta parte aproximadamente (11\%). La discriminación por sexos acusa un número mayor de varones; el porcentaje de niñas (38.9\%) corresponde a la tasa de desarrollo del país (Estados Unidos: 50,8\%; Gran Bretaña: 43\%; México: 37,8\%; Egipto 17,4\%). La enseñanza privada es netamente mayor que la enseñanza oficial, 59\%, sin lograr tener la importancia que el público se imagina en ocasiones“. (LEBRET, 1958, tomo I, p. 316).

\section{SEGUNDA GLOSA: DILEMAS DE LA SECUNDARIA: CLÁSICO/TÉCNICO; ÚNICO/BIFURCADO}

Entre 1893 y 1930 existió una institución para la formación de maestros de secundaria: la Facultad de Filosofía y Letras del Colegio Mayor del Rosario como Facultad universitaria que otorgaba el título de doctor en Filosofía y Letras, destinada a "la formación de directores y catedráticos para los colegios públicos” (CARRASQUILLA, 1909 [1957], t. 2, p. 473), (ORTIZ, 2003, p. 40), (MARTÍNEZ, 2002). No hubo normales para formar maestros de secundaria, al menos hasta 1934. La explicación nos remite al diseño instaurado por el decreto 491 de 1904, pilar del sistema educativo durante la primera mitad del siglo. Allí se establece la Instrucción secundaria en tres ramas: a) Escuelas normales, sólo para formar maestros de escuela primaria b) Instrucción secundaria técnica; y c) Instrucción secundaria clásica o Bachillerato en Filosofía y Letras (MISP, 1904, arts. 107-122).

Este esquema contiene las tensiones y fisuras que debieron afrontar los reformadores del siglo XX. En primer lugar, el Decreto sitúa la formación 
normalista como una rama especializada de la enseñanza secundaria, y aunque esto era ya un ascenso de rango para las normales, constituía una rama paralela pero inferior al bachillerato clásico, pues no daba acceso a los maestros a la instrucción universitaria profesional.

A la formación de maestros de secundaria se le dio rango universitario en un contexto distinto al tipo modelo clásico de la Facultad de Filosofía y Letras, con la fundación de las Facultades de Ciencias de la Educación; desde la efímera Escuela de Ciencias de la Educación de la Universidad de Antioquia (1926-1933), y luego otras tres, efímeras también, las Facultades de Ciencias de la Educación de la Universidad Nacional (1933-1935), la de "Ciencias de la Educación de Señoritas" (Bogotá, 1934-1935) y la de "Ciencias de la Educación de Tunja” (Boyacá, 1934-1935), que fueron fusionadas y reconvertidas en la legendaria Escuela Normal Superior (1936-1951), emblema del gobierno liberal y cuna de las ciencias sociales en el país, pero depositaria paradójica de una disciplina pedagógica que fue reduciendo a sus elementos metodológicos (RÍOS, 2008, 51-91). Cerrada por los gobiernos de la restauración conservadora (19461953), la ENS colombiana dio paso a los formatos de Facultades de Educación de fines de los años 1950, como la de la Universidad de Antioquia (1954), atravesados por una tensión entre "conocimientos disciplinares y conocimientos pedagógicos", que termina en detrimento de estos últimos en la formación de maestros (RÍOS, 2008, p. 253).

En segundo lugar, el Decreto 491 establece una "instrucción secundaria técnica", que comprendía "las nociones generales de cultura general, los idiomas vivos y las materias preparatorias para la instrucción profesional respectiva" (MISP, 1904, art. 116). Otorgaba "el grado de Bachiller en ciencias, indispensable para ingresar a la facultad de matemáticas". Era, en realidad, un bachillerato clásico modificado: compartían los cursos de Religión, Gramática castellana, Geografía, Algebra, Geometría, y Física, pero en el técnico no se daban ni Latín ni Filosofía (salvo la Lógica), y se estudiaban Química general, Cosmografía, Lógica, Dibujo lineal, y Trigonometría rectilínea. El decreto exigía, 
además, como condición para que el Gobierno reconociera los títulos de Bachiller clásico expedidos por establecimientos oficiales o privados, que en éstos se dictaran los cursos requeridos para el Bachillerato de ciencias, “... a fin de que sea potestativo de los alumnos obtener uno u otro título" (art. 122). Se configuraba una ambigua bifurcación del bachillerato, pues el bachillerato técnico no daba acceso al "noble" Bachillerato en Filosofía y Letras. Debe precisarse que este bachillerato técnico no tenía relación con la formación industrial o en Artes y Oficios para obreros y artesanos, que fue constituida como una rama al margen del sistema escalonado, al punto que incluía su propia primaria. Las Escuelas de Artes y Oficios no harán parte de la secundaria sino hasta 1938 (HELG, 1987, p. 260).

Además, como parte de la enseñanza secundaria técnica, el Decreto incluía un bachillerato comercial con su pensum propio -mecanografía, contabilidad-, (art. 119), con lo que se conformaba otra rama paralela e inferior en estatus, pues tampoco conducía a título de Bachiller clásico ni a estudios universitarios. Valga registrar acá que la rama comercial, a diferencia de la formación en Artes y oficios, creció de modo exponencial durante estas cinco décadas del siglo XX, pues se convirtió (en manos privadas) en una salida asequible a las clases en ascenso y el sector femenino, y con mucha más demanda que la otra rama, la del magisterio. Hacia 1958, el diagnóstico de la Misión “Economía y Humanismo” (PELLETIER, 1996), constataba que:

Es bastante sorprendente la desproporción que existe en Colombia entre la enseñanza industrial y la comercial: 6.737 alumnos de un lado y 17.340 del otro. La enseñanza comercial, por lo tanto, es mucho más extensa. [Y...], por otra parte, su rápido desarrollo desde 1946 (un crecimiento de 169\%) y el predominio del sector privado (LEBRET, 1958, p. 315).

Y en tercer lugar, el decreto estatuía el mentado bachillerato en Filosofía y letras, con su pensum humanístico que combinaba lenguas clásicas, matemáticas y filosofía, una combinación que se blindó, ante las críticas, con la 
denominación de cultura general. Los reformadores liberales se debieron batir para secularizar esta noción insertando los currículos las ciencias sociales y la literatura profana.

Así quedaba montada la equívoca dicotomía técnico/clásico, que polarizó el debate sobre las políticas educativas, entre "diversificación" de ramas o "jerarquización" de conocimientos. Un resbaladizo entramado que, en la superficie política, galvanizó las fuerzas políticas y religiosas -la oposición liberal, los conservadores moderados, el clero secular y regular, los pedagogos laicos modernizadores, y a partir de 1927, los expertos de las misiones internacionales (FARRELL, 1974) que se alinearon alrededor de los fines del nuevo sistema educativo y los medios para obtenerlos, en especial con la enseñanza secundaria. Eran tres núcleos conflictivos, que condensaban una maraña de temas asociados: uno, la función elitista del bachillerato, es decir, su cerramiento a la masa de la población que no requería conocimientos eruditos sino prácticos, a lo sumo técnicos; el carácter "tradicionalista" y estéril de las asignaturas de Humanidades Clásicas, en detrimento de los conocimientos y profesiones científicas necesarias para la modernización del país; y la autonomía o debilidad del sistema educativo estatal frente al cuasi monopolio educativo eclesiástico y la autonomía de los poderes privados y los poderes regionales, lo que implicaba la lucha por la frontera entre lo público y lo privado y su control soberano en el sistema educativo nacional.

El Estado finalmente tampoco se interesó en reducir al privado, pues debido a la polarización bipartidista, el mantenimiento de colegios particulares era una estrategia para la sobrevivencia económica e ideológica del partido derrotado de turno (HELG, 1987). Tres nudos que podríamos condensar como Centralización, Modernización y Democratización. Cerremos esta glosa con un dato que sirve para retratar el efecto práctico de esta legislación que estipulaba un modelo cerrado en su jerarquía y diversificación, pero que por otro lado se implementaba por medio de acuerdos, contratos y concesiones prácticamente caso por caso (MARTÍNEZ, 2002). Hacia 1921, Félix Restrepo, jesuita 
especializado en Pedagogía y Educación en Alemania, denunciaba el estado caótico al que había llegado la expedición de los títulos de bachillerato:

Nuestra legislación de Instrucción pública no admite sino dos bachilleratos: clásico y técnico, o sea en Filosofía y Letras y en Ciencias y conforme a esta sencilla y racional clasificación está redactado el Decreto de 16 de septiembre de 1916. Pero en la práctica el Ministerio de Instrucción Pública registra y aprueba toda esta inmensa variedad de títulos, dados unos por Colegios oficiales, otros por colegios privados... (RESTREPO, 1921, p. 133).

A renglón seguido, citaba, como prueba, la lista de títulos académicos otorgados entre 1912 y 1921 :

Diploma de bachiller 1912,

De enseñanza comercial 1912,

De bachiller en enseñanza secundaria 1912,

Diploma comercial 1912,

De bachiller en enseñanza secundaria moderna: 1912, 1915

De bachiller moderno 1912, 1916,

De bachiller técnico 1912,

Bachiller de filosofía y letras 1912,

Bachiller moderno y de competencia comercial 1912,

Título de competencia en enseñanza comercial 1912,

Diploma de bachiller e idoneidad comercial 1914,

Bachiller en ciencias 1915,

Bachiller en ciencias e idiomas modernos 1916,

Bachiller en ciencias comerciales 1916. (RESTREPO, 1921, p. 133).

Y culminaba su diagnóstico con esta perla:

Otros varios títulos semejantes se encuentran en los registros oficiales, pero bastan estos para el caso. Sólo quiero añadir el gran título de 
"Bachiller técnico en humanidades" que por sí solo bastaría mejor que un tratado para probar el desconcierto que reina en esta materia (RESTREPO, 1921, p. 133).

Veremos en su momento, cómo en 1955 se produce otra publicación reitera, para la legislación sobre Planes de Bachillerato, estos síntomas de confusión y bloqueo del bachillerato.

\title{
DOS PROYECTOS DE GOBIERNO EDUCATIVO
}

Monseñor Rafael María Carrasquilla, uno de los cerebros de la reforma educativa entre 1890 y 1920, defendió, junto con un grupo de brillantes pedagogos jesuitas, lasallistas y salesianos el proyecto de los educadores clásicos. Explicando la función de los dos bachilleratos, delineaba así la opción jerarquizadora:

\begin{abstract}
Entrambas educaciones son útiles a la sociedad: la primera [técnico] forma dependientes de casas de comercio, manipuladores de laboratorio, directores de fábricas y minas, ingenieros de puentes y calzadas. Y eso se necesita, y eso basta a la mayoría, que no tiene talento ni tiempo para dedicarse a más de un aprendizaje. La otra educación produce los Gladstone, los Balfour, [...] y ellos se formaron así, con el estudio, durante nueve años, de los autores griegos y latinos, con cinco años de filosofía, con larga meditación de la Escritura Santa y de los antiguos padres de la Iglesia. [...] (CARRASQUILLA, 1909 [1957], p. 277).
\end{abstract}

La tesis de los pedagogos clásicos -los hubo conservadores y liberales, laicos y religiosos- era que "esos estudios (lenguas clásicas y filosofía,) suministran ideas: conocimientos universales, que por universales a todo se aplican” (CARRASQUILLA, 1909 [1957], p.285-287), Los opositores liberales y el ala de conservadores modernizadores -a la que pertenecían el ministro Antonio José Uribe, Pedro Nel Ospina o Carlos E. Restrepo - acusaban a este 
bachillerato de "formar hombres para una sociedad que no existe". En las décadas de 1930 y 1940 lo continuarán haciendo pedagogos liberales defensores de la Escuela Activa como los emblemáticos Agustín Nieto Caballero, Luis López de Mesa, o Gabriel Anzola, que lograron introducir en el pensum, así fuera por pocos años, asignaturas como la sociología o la antropogeografía (SAENZ, SALDARRIAGA, OSPINA, 1997, p. 456). Si se piensa que este debate era "lógico" en los años iniciales del sistema escalonado, con una sociedad aún rural en economía y señorial en cultura política, no parecerá tan claro hallar la defensa de la lengua latina al borde de la década de 1960 (ARIZMENDI, 1959, p. 302).

El proyecto opuesto al humanista podría denominarse liberal, pero, de nuevo las discontinuidades colombianas rompen el esquema. En Colombia, el gobierno conservador de Pedro Nel Ospina, interesado en traer misiones de expertos extranjeros en distintos campos, contrató en 1924 la llamada Misión Pedagógica Alemana, la cual, tras 10 meses de trabajo presentó un amplio proyecto de reforma educativa, que propuso una rearticulación de los niveles escalonados y de las ramas paralelas o marginales. En lo que concierne a la secundaria, propuso un bachillerato diversificado, con un ciclo básico de cuatro años, con titulación que habilitaría para continuar hacia el mercado laboral, o hacia escuelas técnicas o comerciales, o continuar un segundo ciclo de bachillerato. Éste, de tres años, estaría dividido en tres especialidades: la humanística, la científica y la comercial, paralelas pero en igualdad de estatus. Proponía además, por primera vez, abrir los estudios secundarios a las mujeres. En cuanto a lo administrativo, su diseño apuntaba a fortalecer una red de colegios nacionales, financiados centralmente en cada capital de departamento, y la creación de una escuela normal nacional para formar maestros de secundaria. El proyecto apuntaba a fortalecer la red oficial de enseñanza secundaria a fin de "diversificar" y "democratizar" la enseñanza secundaria, reduciendo el rol jerarquizador y selectivo del bachillerato clásico como única vía a estudios superiores. 
La reforma fue desmantelada por la oposición eclesiástica, pero el siguiente gobierno conservador (Miguel Abadía Méndez, 1926-1930), introdujo sutilmente en la legislación una buena parte de las recomendaciones de la Misión e instauró el bachillerato diversificado. Así mismo, tomó una medida inédita: privatizó los colegios de particulares que se sostenían con contratos oficiales, es decir, separó con nitidez la esfera nacional de la esfera privada (MISP. Decreto número 1951 de 1927).

Para resumir los avatares del proyecto de Escuela Unificada en esta mitad del siglo XX colombiano, baste decir que fue reformado y desmantelado varias veces, pues también varias veces se reintentó volver a establecerlo. En 1955, Daniel Henao Henao, Ministro de educación del dictador católico Gustavo Rojas Pinilla, y a propósito de otra nueva reforma de la secundaria, inventarió veintiún planes de estudios que habían sido promulgados entre 1903 y la fecha. De esos, uno en 1932, durante el gobierno liberal de Olaya Herrera, volvió al bachillerato unificado de seis años. Tras otras reformas, en 1942, otro gobierno liberal restablece el bachillerato en dos ciclos (4 y 2 años); a finales de 1945, también bajo otro gobierno liberal, se regresa a los siete años de estudios secundarios. Pero también, el gobierno de ultraderecha de Laureano Gómez, que casi logra instaurar una constitución de corte corporativista, dispone en 1950, un nuevo plan de estudios que "mantiene el plan de los seis años de bachillerato, con cultura mínima obligatoria para todos los colegios” (HENAO, 1955, p.18), pero permite ciertas especializaciones.

El exministro Henao hace este recuento para apuntalar su propia batalla: su sucesor en la cartera, Caicedo Ayerbe, contra todas las recomendaciones de todos los gremios (el primero CONACED, la Confederación de Educadores Católicos fundada en 1938 por un jesuita), acababa de expedir el decreto 925 de 1955, en donde instalaba un bachillerato "básico" de cuatro años y un bachillerato "universitario”, y "daba primacía exagerada al inglés sobre otras lenguas extranjeras...” (HENAO, 1955, p. 19). En dos palabras, era una reforma que retomaba una vez más, 28 años y mediando una explosión 
demográfica y una revuelta política de por medio, las banderas de la Escuela Unificada de la Misión Alemana de 1927. ¿Por fin la democratización?

Aline Helg cuenta un doble desenlace, el de esta reforma y el de todo el proceso de nacionalización y democratización educativa hasta 1957: la reacción contra el decreto de Caycedo, lejos de provenir solamente de la Iglesia católica y del partido conservador, galvanizó contra ella también a los intelectuales y pedagogos liberales propietarios o rectores de los colegios privados más prestigiosos del país: Agustín Nieto Caballero (liberal), Gerardo Molina (marxista) rector de la Universidad Nacional, Nicolás Gaviria (conservador), Luis López de Mesa, ministro de las reformas liberales de 1938, Rafael Bernal Jiménez, sociólogo y pedagogo conservador, el jesuita Félix Restrepo, el exministro conservador Eliseo Arango, al lado del Arzobispo Crisanto Luque, cerraron filas rasgándose las vestiduras contra ese

flagrante atentado contra el prestigio del bachillerato humanístico. Los intelectuales no pensaban aún -a estas alturas- en hacer al bachillerato más flexible, ni abrirlo a una extensa masa de la población (HELG, 1987, p. 280-281).

No sólo cayó la reforma de este dictador católico-populista. La caída del dictador Rojas Pinilla, dos años después, fue acordada por un frente unido de todos los partidos políticos, los gremios y el ejército. Este es su balance general del proceso:

El bachillerato revela un deslinde entre el pueblo y la élite, puesto que sirve de filtro en el ascenso social. Reservado hasta los años 1940 a un pequeño número de jóvenes de las clases superiores, comprende seis años de estudios clásicos. Ante la falta de cuadros y la necesidad de abrir una vía de promoción social para las clases medias citadinas, varios ministros de educación anhelan democratizarlo volviéndolo accesible después de cuatro años de estudio. Esta reforma habría permitido a un mayor número de jóvenes obtener el bachillerato elemental y después seguir una formación técnica, dejando a las élites el privilegio del bachillerato superior que conduciría a la universidad después de dos años de colegio. Pero intelectuales, eclesiásticos, 
pedagogos, y políticos, rehusaron incluso esta democratización parcial con el pretexto de que reduciría el estatus del bachillerato en la sociedad (HELG, 1987, p. 298).

Tras este evento, la jerarquización a dos velocidades de la enseñanza secundaria hizo metástasis produciendo una balkanización de cada uno de los sectores, el público y el privado. Sus efectos han venido siendo cubiertos por un discurso técnico que borra la memoria cultural de las políticas educativas: los historiadores colombianos - incluyendo a Helg - habíamos visto los intentos fallidos de Escuela Única como episodios locales de reforma, discutida y ensayada, a veces por reformadores liberales, otras por conservadores aislados del panorama internacional. Pero el movimiento por la Escuela Unificada,

en un principio [se] trató de lograr un tronco común para la enseñanza secundaria, algo que existía en España, pero no en la mayor parte de los países europeos. Después amplió su programa para defender una enseñanza que no dependa de distinciones económicas, sociales, de sexo, de religión, de raza, de ideología política. [...] se podría resumir el movimiento de la escuela unificada, en una síntesis en la que todos estarían de acuerdo, como una política de la enseñanza y una pedagogía que haga del principio de igualdad de oportunidades una realidad efectiva (RUIZ BERRÍO, 1976).

\section{CONSIDERACIONES FINALES}

La Escuela Única -o unificada, o comprensiva- estaba en relación con una corriente reformadora internacional y con un proceso de luchas y proyectos que han tensionado la construcción de los sistemas educativos nacionales en Europa y América (SIMON; RUBINSTEIN, 1973). Hacia 1923, por citar el evento de la Misión Alemana, Lorenzo Luzuriaga, el prolífico pedagogo escolanovista, acababa de publicar en España su militante libro "La Escuela Unificada" (1922), inspirado en las reformas de Jules Ferry, reclamando para España un verdadero sistema educativo como forma de reivindicar la escuela nacional frente a la escuela de castas (SAVOIE, 2013). 
Así, descubrimos que la discontinuidad colombiana se reproduce en una historia educativa desconectada de los proyectos de reforma democrática de la enseñanza secundaria: esta investigación acaba de constatar que dicha tradición reformista ha sido excluida de la memoria política de la pedagogía en Colombia.

Investigar la tradición política que viene desde los asesores alemanes y culmina en la fallida reforma populista de 1957, se vuelve una necesidad urgente. Habrá que desclasificar los archivos de la historia de la Escuela Única, para actualizar la agenda de las luchas actuales por el "derecho a la educación secundaria para todos" y forzar, una vez más y como siempre, la ampliación del porcentaje de realización de la promesa educativa de la modernidad en nuestro país. Pero la apuesta es muchísimo mayor que superar un borramiento historiográfico. Recientes investigaciones en otros países latinoamericanos nos ayudarán ahora a comprender cada vez mejor dónde y cómo se ubican los efectos estructurales no resueltos en la conformación de las redes y jerarquías (los modelos institucionales) de nuestros sistemas educativos, acudiendo a conceptos como segmentación y sistematización (ACOSTA, 2011). Creo que ellos permiten captar los procesos históricos por los cuales se han constituido tipos de estructuras del sistema educativo, unas más piramidales y segmentadas y otras más horizontales y diversificadas, y saber cómo y dónde podríamos actuar para desplazar a las primeras y tender hacia las segundas, rompiendo el efecto de atrapamiento que cuestionamos al inicio. La viabilidad de nuestras democracias, y por qué no, la refundación de nuestros Estados liberales (SANTOS, 2017) están en juego si no superamos este "cuello de botella" de la enseñanza secundaria.

En las luchas democráticas colombianas, la propuesta de la Escuela Única se inscribe en el propósito de hacer de la educación un lugar de invención: la invención de la igualdad social. La igualdad no es algo dado ni preestablecido, sino un lugar construido por la imaginación y la creatividad. Ya sea como secundaria o bachillerato, se trataría de llegar o salir de ella, como de un laboratorio o de un taller de artesanos, que se las ingenian para la gestación 
de la sociedad que aún no existe. Los estudios secundarios dejarán así, de ser mera capacitación de sujetos productivos o la réplica de la jerarquización social, convirtiéndose en espacios creativos para la comunidad que aún no ha sido pensada: la de los iguales, la de los libres. "Refrescar" - dicen nuestros indígenas misak - la tradición de Tawney para el mundo anglosajón y la de Giner de los Ríos y la ILE para el mundo hispanoamericano.

\section{REFERENCIAS}

ACOSTA, Felicitas. Escuela secundaria y sistemas educativos modernos: análisis histórico comparado de la dinámica de configuración y expansión en países centrales y en la Argentina. Revista HISTEDBR On-line, Campinas, n. 42, p. 3-13, jun. 2011. Disponible en:

http://www.histedbr.fe.unicamp.br/revista/edicoes/42/art01_42.pdf Acceso en: 3 feb. 2018.

ARIZMENDI POSADA, Octavio. Un problema de siempre: el bachillerato. Arco. Revista de las áreas culturales bolivarianas, v. 1, p. 301-305, 1959.

DE CERTEAU, Michel L'Écriture de l'histoire. Paris: Gallimard-Folio, 1975.

CARRASQUILLA, Rafael María. Lo nuevo y lo viejo en la enseñanza. Bogotá, Imp. Eléctrica, 1909. In: Obras Completas. t. III. v. 1. Bogotá: Editora Nacional, 1957. p. 277-335.

\section{Concordato entre la Santa Sede y la República de Colombia. In:}

Conferencias Episcopales de Colombia. t. I. 1908-1953. Bogotá: El Catolicismo, 1956. p. 519-530.

Constitución de la República de Colombia, Bogotá, I de Echeverría, 1886. Disponible en:

http://www.bdigital.unal.edu.co/224/36/constitucion_de_la_republica_1886. pdf._Acceso en: 2 ene. 2018.

FACUNDO, Ángel, ROJAS, Carlos. La calidad de la educación secundaria. Bogotá: M.E.N. Fondo Editorial, 1982.

FARRELL, Robert Vincent. The catholic church and colombian education: $1886-1930$, in search of a tradition. Ph. D. (Dissertation). 
Columbia University, Ann Arbor-Michigan, Xerox University Microfilms, 1974.

FOUCAULT, Michel. La arqueología del saber. México: Siglo XXI Editores, 1970.

GÓMEZ, Víctor, DIAZ, Claudia, CELIS, Enrique. El puente está quebrado ...: aportes a la reconstrucción de la educación media en Colombia. Bogotá: Universidad Nacional de Colombia, Facultad de Ciencias Humanas, 2009.

GÓMEZ, Víctor Manuel. La pirámide de la desigualdad en la educación superior en Colombia. Diversificación y tipología de instituciones. Bogotá: Universidad Nacional, 2015.

HENAO HENAO, Daniel. Veintiún planes de bachillerato. Revista Javeriana, t. XLV, n. 221, p. 15-19, feb. 1956.

HELG, Aline. La educación en Colombia 1918-1957. Una historia social, económica y política. Bogotá: Cerec, 1987.

MALAVER, Carol. De cada 100 graduados, solo 48 ingresaron a la educación superior. El Tiempo, 28 de julio de 2016. Disponible en:

http://www.eltiempo.com/archivo/documento/CMS-16656094. Acceso en: 10 oct. 2017.

MARTÍNEZ SARMIENTO, Liliana. La conformación del Bachillerato en Colombia, 1892-1930. O de cómo hacer funcionar un desorden. 2002. Trabajo de Grado (título de Historiador) - Pontifícia Universidad Javeriana, 2002. http://www.histedbr.fe.unicamp.br/revista/edicoes/42/arto1_42.pdf

LEBRET, Joseph-Louis, O.P. Misión Economía y Humanismo. Estudio sobre las condiciones del desarrollo de Colombia. Bogotá: Aedita Editores, Cromos, 1958.

MIPC (Ministerio de Instrucción Pública de Colombia). Ley 89 de 1892, Diario Oficial., No. 9.023, (dic. 24 de 1892). Disponible en: http://www.suinjuriscol.gov.co/clp/contenidos.dll/Leyes/1631047?fn=documentframe.htm $\$ \mathrm{f}=$ templates $\$ 3.0$ Acceso en: 2 ene. 2018.

MIPC (Ministerio de Instrucción Pública de Colombia). Decreto 349 de 1892, Diario Oficial. No. 9041, ene. 11 de 1893. Disponible en: https://www.mineducacion.gov.co/1759/articles-102504_archivo_pdf.pdf. Acceso en: 2 ene. 2018.

MIPC (Ministerio de Instrucción Pública de Colombia). Ley 39 de 1903. Diario Oficial. $\mathrm{N}^{\circ}$ 11.931, 30 de Octubre de 1903. Disponible en: 
https://www.mineducacion.gov.co/1621/articles-102524_archivo_pdf.pdf Acceso en: 2 ene. 2018.

MIPC (Ministerio de Instrucción Pública de Colombia). Decreto 491 de 1904. (1959). In: Educación Colombiana. Tomo I. Disposiciones orgánicas y reglamentarias de la Educación Nacional, 1903 a 1958. Bogotá: Imprenta Nacional. Disponible en: https://www.mineducacion.gov.co/1621/articles102515_archivo_pdf.pdf Acceso en: 2 ene. 2018.

MEN (Ministerio de Educación Nacional). (1927) Decreto No 1951 de 1927 (diciembre 2), por el cual se reglamenta la enseñanza secundaria. Diario Oficial ( $\mathrm{N}$ 20663). Bogotá, miércoles 7 de diciembre de 1927. Disponible en: https://www.mineducacion.gov.co/1621/articles-102950_archivo_pdf.pdf Acceso en: 2 ene. 2018.

MISP (Ministerio de Instrucción y Salubridad Pública). Ley 56 de 1927 (noviembre 10), por la cual se dictan algunas disposiciones sobre instrucción pública. Diario Oficial. número 20645 Bogotá, 15 de noviembre de 1927. Disponible en: https://www.mineducacion.gov.co/1621/article-102998.html Acceso en: 2 ene. 2018.

MISP (Ministerio de Instrucción y Salubridad Pública). Decreto número 1951 de 1927 (diciembre 2), por el cual se reglamenta la enseñanza secundaria. Diario Oficial. n. 20663. Bogotá, 7 de diciembre de 1927. Disponible en: https://www.mineducacion.gov.co/1621/article-102950.html. Acceso en: 2 ene. 2018.

MEN (Ministerio de Educación Nacional). Decreto número 1487 de 1932 (13 de septiembre) sobre reforma de la enseñanza primaria y secundaria. Diario oficial 22090 Bogotá, 19 de septiembre de 1932. Disponible en: https://www.mineducacion.gov.co/1621/articles-102998_archivo_pdf.pdf. Acceso en: 2 ene. 2018.

MEN (Ministerio de Educación Nacional). Decreto número 1283 de 1935. (julio 17) sobre segunda enseñanza. Diario Oficial 22951. Bogotá, lunes 5 de agosto de 1935. Disponible en: https://www.mineducacion.gov.co/1621/articles102993_archivo_pdf.pdf. Acceso en: 20 jul. 2018.

MEN (Ministerio de Educación Nacional). Decreto número 2214 de 1935 (diciembre 11) por el cual se dictan algunas disposiciones sobre establecimientos de segunda enseñanza. Diario Oficial 23088 Bogotá, lunes 20 de enero de 1936. Disponible en: https://www.mineducacion.gov.co/1621/articles102995_archivo_pdf.pdf. Acceso en: 20 jul. 2018. 
MEN (Ministerio de Educación Nacional). Resolución número 1096, junio 30, por la cual se organiza la expedición y registro de diplomas. In: Educación Colombiana. Tomo I. Disposiciones orgánicas y reglamentarias de la Educación Nacional, 1903 a 1958. Bogotá: Imprenta Nacional. 1958.

MEN (Ministerio de Educación Nacional). Resolución número 2401, noviembre 22, por la cual se reglamentan los exámenes de habilitación, admisión y validación. In: Educación Colombiana. Tomo I. Disposiciones orgánicas y reglamentarias de la Educación Nacional, 1903 a 1958. Bogotá: Imprenta Nacional. 1958

MEN (Ministerio de Educación Nacional). Resolución número 4836 de 1958, octubre 10, por la cual se reglamentan los exámenes en los colegios de bachillerato, y se dictan normas sobre la supervigilancia de os correspondientes en sexto año. In: Educación Colombiana. Tomo I. Disposiciones orgánicas y reglamentarias de la Educación Nacional, 1903 a 1958. Bogotá: Imprenta Nacional. 1958, p. 1009-1013

ORTIZ, Álvaro Pablo. Historia de la Facultad de Filosofía y Letras 18901930. Bogotá: Universidad del Rosario, 2003.

OSSENBACH, Gabriela. Bases para el Avance de la Historia Comparada de la Educación Iberoamericana (Badhicei). In: Zuluaga, Olga y Gabriela Ossenbach (comps). Génesis y desarrollo de los Sistemas Educativos Iberoamericanos Siglo XIX. Bogotá: Editorial Magisterio, 2004. p. 23-66.

PELLETIER, Denis. Économie et humanisme. De l'Utopie communautaire au combat pour le Tiers-Monde, 1941-1966. Paris: Le Cerf, 1996.

PROST, Antoine. Histoire générale de l'enseignement et de l'éducation en France. T. IV. Depuis 1930. Paris: Perrin, 2004.

RINGER, Fritz; MULLER, Detlef, SIMON, Brian (eds). The Rise of the Modern Educational Systems. Structural Change and Social Reproduction 1870-1920, Cambridge and New York: Cambridge University Press, 1987.

RESTREPO, Félix. La segunda enseñanza en Colombia. Horizontes, IX, n. $178,1921$.

RÍOS, Rafael. Las Ciencias de la Educación en Colombia, 1926-1954. Entre universalismo y particularismo cultural. Bogotá: Ed. Magisterio. Grupo Historia de la práctica pedagógica, 2008.

RUIZ BERRÍO, Julio. El significado de la escuela única y sus manifestaciones 
históricas. Revista de educación, n. 242, p. 51-63, ene./feb. 1976.

SAENZ, Javier; SALDARRIAGA, Oscar; OSPINA, Armando. Mirar la infancia. Pedagogía, moral y modernidad en Colombia, 1903-1946.

Medellín, Editorial U. de Antioquia/UniAndes/ Foro Nacional por Colombia/Colciencias, 2 vol, 1997.

SAFFORD, Frank. El ideal de lo práctico, el desafío de formar una élite técnica y empresarial en Colombia. Bogotá: Editorial Universidad Nacional/El Áncora Editores, 1989.

SALDARRIAGA, Oscar. De Universidades a Colegios: la filosofía escolar y la conformación del bachillerato moderno en Colombia, 1792-1892. In: CASTROGÓMEZ, Santiago.; RESTREPO, Eduardo. (ed). Genealogías de la colombianidad. Formaciones discursivas y tecnologías de gobierno en los siglos XIX y XX. Bogotá: Instituto Pensar, 2008. p. 308-332.

SALDARRIAGA, Oscar. La filosofía escolar como disciplina escolar, 1765-1903. En: Congreso Iberoamericano de Historia de la Educación Latinoamericano, 12, 2014 ,Medellín. Memorias XII Congreso Iberoamericano de Historia de la Educación Latinoamericana. Medellín U de A, http://www.udea.edu.co/wps/portal/udea/web/generales/interna/!ut/p/zo/fY 4xD4IwEIV_CwMjaQGDOhJiTAiTJga7mPOoclpapa3x51tIHFyc7l7e94dE6xlQsOLruDIaFBBHoVxWq2rLCoXvNnu6oqXRVVulvtDk6oyVjPxHwgX6P Z8ipIJNNrJt2Ptw4wOlO8kxBzsrrNIL87aevIeZx_ibnX1EEnbQIYxkAIdqIugF65yYi57DwCUoR5dM715M6lIWhm VpENpIn5IAczEtgEqZcKkoynBXvcxfEDD8x2GQ!!/

SANTOS, Boaventura de Sousa. Refundación del Estado en América Latina. Perspectivas desde una epistemología del Sur. Bogotá: Siglo del Hombre Editores/Uniandes/Siglo XXI editores, 2017.

SAVOIE, Philippe. La construction de l'enseignement secondaire 18021914. Paris: ENS Éditions, 2013.

SIMON, Brian; RUBINSTEIN, David. The Evolution of the Comprehensive School 1926-1972. Routledge and Kegan Paul, London, 1973 .

TAWNEY, R. H., La segunda enseñanza para todos. Madrid: Publicaciones de la Revista de Pedagogía. Trad. Lorenzo Luzuriaga. [1924] 1932.

VIÑAO FRAGO, Antonio. Sistemas educativos, culturas escolares y reformas: cambios y continuidades. Madrid: Morata, 2002. 
VIÑAO FRAGO, Antonio. Del bachillerato de elite a la educación secundaria para todos (España, siglo XX). In: VICENTE Y GUERRERO, Guillermo (coord. y ed.). Historia de la Enseñanza Media en Aragón. Zaragoza: Institución "Fernando el Católico", 2011a. p. 449-472. Disponible en:

https://ifc.dpz.es/recursos/publicaciones/30/71/12vinao.pdf. Acceso en: 21 oct. 2018.

VIÑAO FRAGO, Antonio. El bachillerato, pasado, presente, futuro. CEE

Participación Educativa, p. 30-44, 17 julio 2011b. Disponible en:

https://www.researchgate.net/publication/317616687El_bachillerato_pasado_ presente_futuro. Acceso en: 2 ene. 2018.

UNIVERSIA. El derecho a la educación en Colombia: Disponible en: http://noticias.universia.net.co/actualidad/noticia/2014/1 2/o9/1116754/derecho-educacion-colombia.html. Acceso en: 10 oct. 2017.

OSCAR DE JESUS SALDARRIAGA é Historiador, Doctor en Filosofía y LetrasHistoria (Université catholique de Louvain); professor titular de la Facultad de Ciencias Sociales-Pontificia Universidad Javeriana-Bogotá. Miembro fundador del Grupo de Historia de la práctica pedagógica en Colombia.

E-mail: oskaldarri@gmail.com

(b) http://orcid.org/0000-0002-3661-0586

RAFAEL GALINDO REYES é Professor e investigador de lá Pontificia Universidade javeriana de Bogotá. Licenciado em Filosofia y Letras de lá Universidade Santo Tomas, Magister em Filosofia Pontifícia Universidade Javeriana. Membro dele Grupo de lá Historia de lá Prática Pedagógica em Colômbia.

E-mail: reyes@javeriana.edu.co

(D) http://orcid.org/0000-0001-8359-1915

Recebido em: 14 de dezembro de 2019

Aprovado em: 16 de janeiro de 2020 
Revista História da Educação (Online), 2020, v. 24: e98995 DOI: http://doi.org/10.1590/2236-3459/98995
e-ISSN: $2236-3459$ http://seer.ufrgs.br/asphe

\footnotetext{
(c) (P)

Revista História da Educação - RHE

Associação Sul-Rio-Grandense de Pesquisadores em História da Educação - Asphe

Artigo de acesso aberto distribuído nos termos de licença Creative Commons.
} 